\title{
Nursing management of fatigue in cancer patients and suggestions for clinical practice: a mixed methods study
}

\author{
Angela Tolotti ${ }^{1}$, Loris Bonetti ${ }^{12^{*}}$, Carla Pedrazzani ${ }^{2}$, Monica Bianchi ${ }^{2}$, Laura Moser ${ }^{3}$, Nicola Pagnucci ${ }^{4}$, \\ Davide Sari ${ }^{5}$ and Dario Valcarenghi ${ }^{1}$
}

\begin{abstract}
Background: Fatigue is a complex and frequent symptom in cancer patients, influencing their quality of life, but it is still underestimated and undertreated in clinical practice. The aims of this study were to detect the presence of fatigue in cancer patients, describe how patients and nurses perceived it and how nurses managed fatigue.

Methods: This is a mixed methods study. Data were collected in two oncological wards using the Brief Fatigue Inventory (BFI), an ad hoc questionnaire, patient interviews, focus groups with nurses and the review of nursing records. Interviews and focus groups were analysed through thematic analysis. We used SPSS 22.0 for quantitative data and Nvivo 10 for qualitative data analysis.

Results: A total of 71 questionnaires were analysed (39 males, mean age 65.7 years). Fatigue was reported 5 times (7\%) in nursing records, while in 17 cases (23.9\%) problems associated to it were reported. Twelve patients were interviewed. Five themes were identified: feeling powerless and aggressive, my strategies or what helps me, feeling reassured by the presence of family members, feeling reassured by nurses' gestures, and being informed. Three themes were identified through the focus groups: objectivity and subjectivity in the assessment of fatigue, nurses' contribution to the multidisciplinary management of fatigue, and difficulty in evaluating outcomes.

Conclusions: The approach to the management of fatigue was unstructured. Patients were satisfied with the care they received but needed more information and specific interventions. Useful aspects were identified that could be used to change health professionals' approach towards the management of fatigue.
\end{abstract}

Keywords: Fatigue, Neoplasm, Nurse, Mixed methods

\section{Background}

Fatigue is a very frequent and common symptom in cancer patients, with an incidence ranging between 80 and $100 \%$ [1-3]. It is a short- and long-term side effect of most anti-cancer treatments and a

\footnotetext{
*Correspondence: loris.bonetti@eoc.ch; loris.bonetti@supsi.ch

${ }^{1}$ Nursing Research and Development Unit, Oncology Institute of Southern

Switzerland (IOSI), Via Gallino, 12, 6500 Bellinzona, Switzerland

2Department of Business Economics, Health and Social Care, University of

Applied Sciences and Arts of Southern Switzerland (SUPSI), Manno, Switzerland

Full list of author information is available at the end of the article
}

consequence of cancer itself, with an onset that may occur at any stage of the cancer disease, from its diagnosis to many years after treatment ends $[1,4-$ 6].

The National Comprehensive Cancer Network $(\mathrm{NCCN})[1,6]$ defines fatigue as "a distressing, persistent, subjective sense of physical, emotional, and/ or cognitive tiredness or exhaustion related to cancer or cancer treatment that is not proportional to recent activity and interferes with usual functioning".

(c) The Author(s). 2021 Open Access This article is licensed under a Creative Commons Attribution 4.0 International License, which permits use, sharing, adaptation, distribution and reproduction in any medium or format, as long as you give appropriate credit to the original author(s) and the source, provide a link to the Creative Commons licence, and indicate if changes were made. The images or other third party material in this article are included in the article's Creative Commons licence, unless indicated otherwise in a credit line to the material. If material is not included in the article's Creative Commons licence and your intended use is not permitted by statutory regulation or exceeds the permitted use, you will need to obtain permission directly from the copyright holder. To view a copy of this licence, visit http://creativecommons.org/licenses/by/4.0/ The Creative Commons Public Domain Dedication waiver (http://creativecommons.org/publicdomain/zero/1.0/) applies to the data made available in this article, unless otherwise stated in a credit line to the data. 
The aetiology of fatigue is complex and multidimensional and it is rarely an isolated symptom, which makes its management partucularly difficult $[1,4,6-8]$.

Fatigue is a symptom that for a long time has been disregarded and underrated, which has had a strong impact on patients' psychological, physical, and social wellbeing, and therefore on their quality of life, limiting their ability to carry out certain roles, maintain an active social life and cultivate interests and hobbies [9]. Patients describe fatigue as the most destabilizing and distressing symptom [8], which never disappears even with rest and sleep [9]. Therefore, in addition to causing stress and anxiety in patients even for a long time, fatigue may have consequences also for family members or carers [10].

According to the several guidelines on cancer-related fatigue published in the last few years [6], the early screening and assessment of fatigue are key prerequisites for the implemention of individualized and effective patient care [11]. Despite they are strongly recommended in the literature, they are often not routinely performed in clinical practice contributing to their underestimation and undertreatment $[1,3,5,12-18]$. According to the literature, the main barriers to conducting a structured and complete assessment of fatigue appear to be the lack of precise knowledge about fatigue, its impact on patients, and of the treatment options [16]. In addition, patients and/or their family members often do not report this symptom because they fear that this might entail a reduction or interruption of their treatment, or think fatigue is inevitable and that nothing can be done about it, or simply because they are afraid of complaining too much [19-21].

Therefore, the management of fatigue is a significant challenge for health professionals, and informing and educating patients and their family members to identify and treat it is an integral part of the caring process [1].

In the literature, there is much evidence about the effectiveness of specific interventions [1, 6, 13, 21-23]. There is in particular strong agreement regarding the usefulness of maintaining or promoting moderate physical activity in patients during and after cancer treatment $[1,22]$. Due to the multidimensional nature of fatigue, mainly non-pharmacological approaches are recognized to be useful in improving quality of life in these patients during active cancer treatments but also after treatment [1, 24-29]. The importance of an interdisciplinary approach, information and education for patients and relatives is also emphasized [6]. Despite the abundance of literature and guidelines addressing this topic, fatigue is still inadeguately and inconsistently addressed in many institutions $[30,31]$ where, like in the one where this study was conducted, no standard protocols were in place for the management of fatigue. It is also important to identify effective barriers that lead health professionals to underestimate fatigue and leave it unaddressed in clinical practice, and to understand what are the perceptions of the patients affected by fatigue, to improve its management and the patients' quality of life. To our knowledge, few studies include an analysis of fatigue based both on the patients' and the nurses' perspectives. Furthermore, no mixed method studies were found on this topic.

The aim of the present study was to detect the presence and degree of fatigue in cancer patients, and describe the perceptions of patients and nurses when detecting and assessing this symptom. The secondary objective was to describe how cancer related fatigue is concretely addressed in clinical practice by nurses. In order to have a broader picture and a more in-depth understanding of the phenomenon from different perspectives, we decided to conduct a mixed-method study.

The research questions for this study were:

1. What are the perspectives of patients and nurses regarding the management of fatigue?

2. How can we quantify fatigue in patients and explore to what extent aspects of care and the management of this phenomenon are reported in nursing records?

3. Do the patients' and nurses' quantitative and qualitative data regarding their perspectives on the management of fatigue match each other?

\section{Methods}

Design

This is a mixed-methods study using a convergent parallel design consisting of a patient survey, patient interviews, focus groups with nurses, and the review of nursing records [32, 33]. We adopted a mixed-method design to gain a deeper understanding of fatigue.

\section{Setting}

Two oncology wards of the Oncology Institute of Southern Switzerland (IOSI).

The first ward is an haematological unit with 11 beds and almost 600 admissions per year. The mean length of stay (LOS) is 3 weeks. The nursing team includes 29 health professionals (clinical nurse specialists, registered nurses and nursing aids).

The second ward is a radiotherapy unit, with 13 beds and almost 800 admissions per year. The mean LOS is 2 weeks. The nursing team includes 18 health professionals (clinical nurse specialists, registered nurses and nursing aids).

\section{Participants \\ Inclusion criteria}

- all cancer inpatients able to reply to a questionnaire in Italian and to complete a numerical rating scale; 
- nurses working in the two oncology wards of the Oncology Institute of Southern Switzerland (IOSI).

\section{Exclusion criteria}

- paediatric patients

\section{Data collection \\ Quantitative data}

The questionnaires were distributed and collected by the nurses working in the participating wards. To assess fatigue, we used the Italian version of the Brief Fatigue Inventory (BFI) [34, 35], that showed a good level of validity and reliability (Cronbach's alpha $=.94$ ) [35]. The BFI was administered to patients twice, upon admission and at discharge, to check if the level of fatigue had changed during hospital stay. The research team trained the ward nurses how to collect the data. When an eligible patient was found, the ward nurses illustrated the study, obtained the informed consent, and administered the questionnaire. Patients who were not affected by fatigue according to the BFI upon admission, were excluded from the study. Patients were also asked to complete a questionnaire that investigated how nurses had managed their fatigue, according to the patients' perception. Through the questionnaire, the patients were asked to state if they had reported their fatigue to the nurses, or if the nurses had detected it. To these two first questions, patients could reply: 'Never', "At least once', or 'Many times'. Patients were then asked if the nurses had implemented some interventions, which in the literature are reported to be useful to treat fatigue and facilitate rest. To these questions the patients could reply either 'yes', 'partly', or 'no'. Finally, they were asked if the nurses had involved other specialists to treat their fatigue. To this question they could reply either 'yes' or 'no'. The questionnaire was pilot tested to check its internal and face validity, and its clarity, with five oncology nurses and five patients, showing a good level of performance with regard to the above characteristics. At the end of the questionnaire, also some of the patients' demographic data were collected.

To evaluate how fatigue was managed by the nurses, three members of the research team (AT, LB and DV) reviewed the clinical records of the patients included in the study, to identify which focuses were adopted in relation to the patients' problems. A focus could be a nursing diagnosis, a patient problem, a sign or symptom, a change in the patient's condition, or any other significant event [36]. Then, we checked which goals and interventions were hypothesized and implemented by the nurses.

\section{Qualitative data}

Semi-structured interviews and focus groups were conducted to further explore the patients' and nurses' experiences about fatigue. The patients were chosen from those who had completed the questionnaires and agreed to be interviewed. The selection was based on the wards, age, and sex, until the number of patients was sufficient to achieve data saturation [32, 37].

The ward nurses identified the elegibile patients and contacted the members of the research team to conduct the interview. The interviews were conducted by two members of the research team (AT and DV), experts in qualitative methods, in the room of the patient, if she/he was alone, or in a quiet dedicated room without external interferences.

The focus groups were conducted with the nurses who were working in the wards involved in the study. The invited nurses were selected by the research team, in agreement with the two head nurses of the unit, who identified which nurses to involve in the study, based on inclusion criteria and availability. Both the patient interviews and focus groups were audio recorded and transcribed verbatim.

\section{Data analysis \\ Quantitative data}

Quantitative data were analysed using SPSS 22.0. A descriptive analysis of the main variables was conducted. The nominal variables were represented in terms of frequency and percentages, and the ordinal or continuous variables respectively in terms of medians, quartiles, means and standard deviations. To compare the groups based on the qualitative variables, the Chi square or Fisher test were used. The Mann Whitney test or $t$ test for unpaired groups were used to compare the ordinal or continuous variables, respectively, if the distribution was normal. We used the Wilcoxon test or the t-test for paired groups to compare the BFI score at the beginning of hospital stay and at discharge. The KolmogorovSmirnov normality test was used to determine the normality of the distributions of the continuous variables [37]. The significance level was set at $p<0.05$.

\section{Qualitative data}

For the qualitative data, we repeatedly read the whole transcript and then conducted a line-by-line thematic analysis [37-40].

We identified the similarities and differences between the themes related to the patients and those related to the nurses. The analysis was conducted by two expert qualitative researchers, using NVivo 10 software. The methodological rigour of the study was supported by the criteria described by Guba and Lincoln (1981) [41]: 
credibility, transferability, dependability, confirmability, and fittingness (Carnevale, 2002) [42].

With regard to reflexivity, "bracketing" was adopted to avoid prejudices. The use of a 'reflective diary', synthesis, and reflection was helpful to differentiate between what participants said and what researchers understood. Two researchers independently coded the texts of the interviews and the focus groups, to ensure the credibility and transferability of the study. Regarding auditability, all the decisions regarding data collection and analysis made by the researchers were documented using field notes, memos and a reflexivity journal. Fittingness was promoted by various checks with the researchers to ensure that interpretations were consistent with the experiences of the interviewees.

\section{Quantitative and qualitative data integration and rigor in relational to mixed methods research}

To integrate qualitative and quantitative data, we used a Joint Display. Fetters et al. [43], defined Joint Displays as a way to "integrate the data by bringing the data together through a visual means to draw out new insights beyond the information gained from the separate quantitative and qualitative results."

Following some examples reported in the literature [44-46], we created a table in which we linked qualitative themes with the quantitative results, searching for agreement and disagreement between the two perspectives. Then we added a column with a comment and integrated the findings in a descriptive way.

To guarantee rigor, based on mixed method literature, we used the following legitimation criteria [47, 48]: Commensurability approximation legitimation, Insiteoutside legitimation, Integration legitimation, Paradigmatic legitimation, Sample integration legitimation, Sequential legitimation, Socio-political legitimation, Weakness minimisation legitimation. A full description of each of them is reported online in Additional file 1.

\section{Results}

\section{Survey results}

Data were collected from January to November 2017. A total of 71 out of 101 (response rate $=70 \%$ ) BFI questionnaires were returned upon patient admission, and validly completed to be analyzed. Twenty-two patients completed the questionnaire also at discharge and of these, 20 completed also the questionnaire on the perception of nursing care received in relation to fatigue.

The sample mainly consisted of men (54.9\%) and haematological cancer patients (52.1\%). The main characteristics of the patients are reported in Table 1.

A total of 48 participants had experienced episodes of fatigue in the previous 7 days before admission. Fatigue interfered mainly with work activities (median $=5 \mathrm{IQR}$
Table 1 Participant characteristics

\begin{tabular}{ll}
\hline Characteristics & $\mathbf{N}=\mathbf{7 1}$ \\
\hline Age- Mean ( \pm SD) & $65.7( \pm 14)$ \\
Sex (\%) & $\mathbf{n}(\%)$ \\
M (\%) & $39(54.9)$ \\
F (\%) & $32(45.1)$ \\
BMI (Me [Q1; Q3]) & $23.4[20.8 ;$ \\
LOS (Me [Q1; Q3]) & $27.2]$ \\
Pathology & $6[12 ; 20]$ \\
Haematology & $\mathbf{n}(\%)$ \\
Solid tumor & $37(52.1)$ \\
Both & $33(46.5)$ \\
Fatigue in the physicians' records & $1(1.4)$ \\
Yes & $\mathbf{n}(\%)$ \\
No & $15(21.1)$ \\
Fatigue in nurses' records & $56(78.9)$ \\
Yes & $\mathbf{n}(\%)$ \\
No & $5(7)$ \\
Other symptoms related to fatigue in nurses' & $\mathbf{n}(\%)$ \\
records & $66(93)$ \\
Yes & $17(23.9)$ \\
No & $54(76.1)$ \\
\hline Ab &
\end{tabular}

Abbreviations: BMI Body Mass Index, LOS length of Stay, Me median, Q1 first quartile, Q3 third quartile, $S D$ Standard deviation

$[2 ; 8])$, followed by their ability to walk, physical activity in general, and enjoyment of life. The worst level of fatigue in the last $24 \mathrm{~h}$ produced a median score of $7 \mathrm{IQR}$ $[5 ; 8]$. There were no significant differences in the values of the BFI items for sex, type of cancer or LOS (short = $<5$ days; average $=6-15$ days; long $>15$ days). Neither were there significant differences between the BFI score upon admission and at discharge (Table 2).

Fatigue was reported 15 times in the medical records. The nurses detected fatigue 5 times, whereas on 17 occasions they reported problems associated with fatigue (e.g. mobility problems, increased soporous state, reduced appetite, and generalized tiredness). In the patient records, no specific interventions implemented by nurses aimed at managing fatigue were found.

With regard to patients' perceptions of nursing care received, $68.8 \%$ reported that nurses had paid attention to their fatigue several times. Regarding actions taken by nurses to deal with fatigue, we found that no information was provided on how to subdivide the day in $45.5 \%$ of the cases, reduce efforts in $46.2 \%$ of the cases, and measure fatigue autonomously in $54.5 \%$ of the cases. Instead, information was provided on how to ask others to do some activities for them in $53.8 \%$ of the cases. According to the patients' perceptions, nurses provided 
Table 2 Brief Fatigue Inventory $(B F I)$ results $(N=71)$

\begin{tabular}{|c|c|c|c|c|c|c|c|c|c|c|c|}
\hline \multicolumn{4}{|l|}{ Tiredness in the last 7 days $^{a}$} & \multicolumn{8}{|c|}{$\mathrm{N}(\%)$} \\
\hline \multicolumn{4}{|l|}{ Yes } & \multicolumn{8}{|c|}{$48(66.7)$} \\
\hline \multicolumn{4}{|l|}{ No } & \multicolumn{8}{|c|}{$15(21.1)$} \\
\hline \multicolumn{4}{|l|}{ BFI scores } & \multicolumn{2}{|c|}{ Mean } & $\pm \mathrm{SD}$ & Me & \multicolumn{3}{|l|}{ Q1 } & Q3 \\
\hline \multicolumn{4}{|l|}{ Level of fatigue right now } & \multicolumn{2}{|l|}{5.3} & 2.5 & 5 & \multicolumn{3}{|l|}{3} & 7 \\
\hline \multicolumn{4}{|l|}{ Usual level of fatigue } & \multicolumn{2}{|l|}{5.2} & 2.5 & 5 & \multicolumn{3}{|l|}{3} & 7 \\
\hline \multicolumn{4}{|l|}{ Worst level of fatigue in the last $24 \mathrm{~h}$} & \multicolumn{2}{|l|}{6.2} & 2.5 & 7 & \multicolumn{3}{|l|}{5} & 8 \\
\hline \multicolumn{4}{|l|}{ How fatigue interfered in the last $24 \mathrm{~h}$ with your: } & \multicolumn{2}{|c|}{ Mean } & $\pm S D$ & Me & \multicolumn{3}{|l|}{ Q1 } & Q3 \\
\hline \multicolumn{4}{|l|}{ General activity } & \multicolumn{2}{|l|}{4.5} & 3.3 & 4 & \multicolumn{3}{|l|}{1} & 8 \\
\hline \multicolumn{4}{|l|}{ Mood } & \multicolumn{2}{|l|}{3.5} & 3.1 & 4 & \multicolumn{3}{|l|}{0} & 6 \\
\hline \multicolumn{4}{|l|}{ Walking ability } & \multicolumn{2}{|l|}{4.7} & 3.2 & 5 & 2 & & & 8 \\
\hline Normal work & & & & 4.9 & & 3.4 & 5 & 2 & & & 8 \\
\hline Relations with other people & & & & 3.3 & & 3.1 & 3 & 0 & & & 6 \\
\hline Enjoyment of life & & & & 4.4 & & 3.6 & 4 & 1 & & & 8 \\
\hline BFI results admission vs discharge $(N=22)$ & & & & & & & & & & & \\
\hline & Admiss & & & & & Discha & & & & & \\
\hline BFI scores ${ }^{a}$ & Mean & $\pm \mathrm{SD}$ & Me & Q1 & Q3 & Mean & $\pm \mathrm{SD}$ & Me & Q1 & Q3 & $p$-value \\
\hline Level of fatigue right now & 4.5 & 2.7 & 4.0 & 2.8 & 7.0 & 4.5 & 2.8 & 4.0 & 1.8 & 7.0 & 0.8 \\
\hline Usual level of fatigue & 4.3 & 2.6 & 4.0 & 2.0 & 6.3 & 4.9 & 2.8 & 5.5 & 3.5 & 7.0 & 0.3 \\
\hline Worst level of fatigue in the last $24 \mathrm{~h}$ & 5.2 & 2.8 & 5.5 & 3.0 & 7.3 & 5.5 & 3.1 & 6.0 & 4.0 & 8.0 & 0.2 \\
\hline How fatigue interfered in the last $24 \mathrm{~h}$ with your: & Mean & $\pm \mathrm{SD}$ & $\mathrm{Me}$ & Q1 & Q3 & Mean & $\pm S D$ & Me & Q1 & Q3 & $p$-value \\
\hline General activity & 3.5 & 3.1 & 3.0 & 1.0 & 5.3 & 4.3 & 3.1 & 5.0 & 1.0 & 7.0 & 0.2 \\
\hline Mood & 3.0 & 3.1 & 2.0 & 0.8 & 4.3 & 3.1 & 2.7 & 2.0 & 1.0 & 6.0 & 0.9 \\
\hline Walking ability & 3.7 & 3.1 & 3.0 & 1.0 & 6.5 & 3.5 & 2.9 & 3.0 & 0.0 & 6.0 & 0.7 \\
\hline Normal work & 4.2 & 3.8 & 3.5 & 0.3 & 8.0 & 4.1 & 3.8 & 3.5 & 0.0 & 7.3 & 0.7 \\
\hline Relations with other people & 3.3 & 3.1 & 2.5 & 0.0 & 6.3 & 2.9 & 2.9 & 2.0 & 0.0 & 5.5 & 0.7 \\
\hline Enjoyment of life & 3.6 & 3.4 & 2.0 & 1.0 & 6.5 & 2.8 & 3.1 & 1.0 & 0.0 & 5.8 & 0.3 \\
\hline LOS & 10.1 & 10.0 & 6.0 & 3.0 & 16.5 & & & & & & \\
\hline
\end{tabular}

Abbreviations: LOS length of Stay, Me median, Q1 first quartile, Q3 third quartile, SD Standard deviation amissing data

reassurance and psychological support (57.1\%), and periodically checked the level of fatigue (46\%). In $53.3 \%$ of the cases, they did not check or ask what the causes of fatigue could be and in $46.7 \%$ of the cases they did not encourage distraction. In $50 \%$ of the cases, they implemented interventions for other symptoms, such as pain and dyspnoea. Finally, they tended to avoid requesting consultation services by other professionals (Table 3).

\section{Patients' perceptions (from interviews)}

Between March-November 2017, 12 patients were interviewed, 5 males and 7 females aged between 34 and 82 years.

Five themes were identified: Theme I: "feeling powerless and aggressive", Theme II "my strategies or what helps me" Theme III "feeling reassured by the presence of family members", Theme IV "feeling reassured by nurse's gestures", Theme V "being informed".

\section{Theme l: "Feeling powerless and aggressive"}

All the patients names reported in the tables are pseudonyms.

\section{It changes you, you are different}

Patients described fatigue as something that impacted them both physically and psychologically, and influenced their perceptions and senses. They reported how this symptom manifests suddenly, and makes them feel unable to do anything (Table 4, quote 1). Some patients felt powerless, others instead reacted aggressively, although this was unusual for them (Table 4, quote 2). Fatigue manifested at different times of the day, some felt it in 
Table 3 Questionnaire on patients' perceptions about care received by nurses to manage their fatigue

\begin{tabular}{|c|c|c|c|}
\hline$(N=20)^{a}$ & $\begin{array}{l}\text { Never } \\
\mathrm{N}(\%)\end{array}$ & $\begin{array}{l}\text { At least once } \\
\mathrm{N}(\%)\end{array}$ & $\begin{array}{l}\text { Several } \\
\text { times } \\
\mathrm{N}(\%)\end{array}$ \\
\hline Did you inform the nurses who were caring for you about your fatigue? & $\begin{array}{l}5 \\
(29.3)\end{array}$ & $4(23.5)$ & $8(47.1)$ \\
\hline Do you think the nurses paid attention to your fatigue? & 0 & $5(31.2)$ & $11(68.8)$ \\
\hline $\begin{array}{l}\text { Of the actions listed below, were there any that made you feel better and that the nurses } \\
\text { performed? }\end{array}$ & $\begin{array}{l}\text { Yes } \\
\mathrm{N}(\%)\end{array}$ & $\begin{array}{l}\text { Partly } \\
\mathrm{N}(\%)\end{array}$ & $\begin{array}{l}\text { No } \\
\mathrm{N}(\%)\end{array}$ \\
\hline \multicolumn{4}{|l|}{ Information/suggestions on how to: } \\
\hline$\triangleright$ Subdivide the day & $\begin{array}{l}4 \\
(36.4)\end{array}$ & $2(18.2)$ & $5(45.5)$ \\
\hline$\triangleright$ Reduce efforts & $\begin{array}{l}5 \\
(38.5)\end{array}$ & $2(15.4)$ & $6(46.2)$ \\
\hline$\triangleright$ Ask others to do some activities & $\begin{array}{l}7 \\
(53.8)\end{array}$ & $1(7.7)$ & $5(38.5)$ \\
\hline$\triangleright$ Measure fatigue by yourself & $\begin{array}{l}4 \\
(36.4)\end{array}$ & $1(9.1)$ & $6(54.5)$ \\
\hline Reassurance and/or psychological support & $\begin{array}{l}8 \\
(57.1)\end{array}$ & $2(14.3)$ & $4(28.6)$ \\
\hline Periodic check of level of fatigue & $\begin{array}{l}7 \\
(46.7)\end{array}$ & $2(13.3)$ & $6(40)$ \\
\hline Interviews \& follow ups to understand the cause of your fatigue & $\begin{array}{l}5 \\
(33.3)\end{array}$ & $2(13.3)$ & $8(53.3)$ \\
\hline Encouraged to distract yourself (e.g.: music, games, reading, etc.) & $\begin{array}{l}5 \\
(33.3)\end{array}$ & $3(20)$ & $7(46.7)$ \\
\hline Help to keep activity levels to the minimum & $\begin{array}{l}5 \\
(33.3)\end{array}$ & $6(40)$ & $4(26.7)$ \\
\hline Involvement of specialists: & $\begin{array}{l}\text { Yes } \\
\mathrm{N}(\%)\end{array}$ & $\begin{array}{l}\text { No } \\
\mathrm{N}(\%)\end{array}$ & \\
\hline$\triangleright$ For mobilization (physiatrists, physiotherapists) & $\begin{array}{l}8 \\
(53.3)\end{array}$ & $7(46.7)$ & \\
\hline$\triangleright$ With massages & $1(7.1)$ & $13(92.9)$ & \\
\hline$\triangleright$ For psychological support (psychologists, etc.) & $\begin{array}{l}2 \\
(14.3)\end{array}$ & $12(85.7)$ & \\
\hline \multirow[t]{2}{*}{$\triangleright$ For nutritional support (nutritionists, dietitians, etc.) } & $\begin{array}{l}4 \\
(26.7)\end{array}$ & $11(73.3)$ & \\
\hline & $\begin{array}{l}\text { Yes } \\
\mathrm{N}(\%)\end{array}$ & $\begin{array}{l}\text { Partly } \\
\mathrm{N}(\%)\end{array}$ & $\begin{array}{l}\text { No } \\
\mathrm{N}(\%)\end{array}$ \\
\hline Interventions to facilitate sleep/rest & $\begin{array}{l}4 \\
(26.7)\end{array}$ & $5(33.3)$ & $6(40)$ \\
\hline Treatment of other symptoms (e.g. pain, dyspnoea ...) & $7(50)$ & $3(21.4)$ & $4(28.6)$ \\
\hline
\end{tabular}

amissing data

the morning, others in the evening, and others throughout the day.

\section{Influences habits and social relations}

Patients reported how strenuous it was for them to carry out their daily living activities or to stay in places where there were many people, such as supermarkets. Everything became hard and undesirable, described as 'too much' for their physical and emotional resources (Table 4, quote 3).
Fatigue and the disease also significantly changed the person's roles in terms of relations, both in daily life and at work. People ended up depending on others and this caused psychological suffering (Table 4, quote 4).

Some patients also reported about problems with concentrating and short-term memory, which impacted also on their jobs (Table 4, quote 5).

\section{Theme II "My strategies or what helps me"}

Some patients thought that forcing themselves to do certain things, like going up the stairs, doing yoga, some 
Table 4 Quotes Theme I: Feeling powerless and aggressive

Quote 1, Paolo": "it started suddenly without a reason, I no longer do anything, almost as if I went in hibernation. I'm just the ghost of myself."

Quote 2, Simona: "I had an episode of aggressiveness, by nature I'm not an aggressive person, but for a silly thing I suddenly flared up and shouted!"."

Quote 3, Giulia: "you no longer feel like reading, like taking your life in your hands, you no longer feel like going to the supermarket, you choose a time when there's no-one, because when you are unwell everything seems too much"

Quote 4, Paola "there were times when I couldn't go out of my home. It was tremendous because I've always been independent."

Quote 5, Elena: "I'm a teacher and I tried to mark my students' work, but I realized that when I edited the file, I no longer remembered what my student had written."

aAll the patients' names reported in the tables are pseudonyms

manual work, and going out for a walk, helped them to cope with tiredness. They reported that it was also important to 'throw it all out', like shouting for instance.

The need to rest was considered to be important, as well as maintaining the normal sleep-wake cycle (Table 5, quote 1).

Some reported that the only thing they could do was to act on will power and do some physical exercise, like standing up from the chair. When fatigue arrives, some patients said: "I sit and wait", as if all they could do was wait until it passed away or got better (Table 5, quote 2).

When fatigue prevails, you end up having bad thoughts, therefore it is important to listen to your own body, avoiding negative things or people, and concentrating on positive things (Table 5 , quote 3 ).

\section{Theme III "Feeling reassured by the presence of family members"}

Family members and friends are a very important resource (Table 6, quote 1 ).

Receiving visits from friends or relatives is important because 'you talk about other things', as if they felt the need to shift their attention from something that caused pain and immobility to 'other things'. Patients reported that when they feel 'melancholic' they feel comforted and strong thanks to the presence and support of their family members and friends. Being surrounded and at the centre of other's affection and attention was very important for the patients (Table 6, quote 2).

Table 5 Quotes for Theme II: "My strategies or what helps me" Quote 1, Simona "when I'm tired, I go up and down the stairs a couple of times, I try to make the effort, then I rest, I do yoga breathing, I shout out, and throw it all out"

Quote 2 Lory "It is important to act on will power, I try to stand up from the chair and if fatigue arrives, I sit down and wait until it passes away or gets better. In these moments, I try to read or listen to music, and think that it will go away just like it came."

Quote 3, Giulia "I listen to my body very much, I try to avoid what is not good, whatever weighs down on me or negative people. I do some cleaning."
Table 6 Quotes for Theme III: "Feeling reassured by the presence of family members"

Quote 1, Paolo "I have a fantastic wife, she is very active and also the kids, they are there whenever I'm in need, they are an important reference point. At home my wife lets me do things my way. She understands me." Quote 2 Agata: "I have a wonderful family ... my husband ... my daughters ... my best friend, I call her my coach. My nephews and nieces are tremendous ... their smiles give me energy.

\section{Theme IV: "Feeling reassured by nurses' gestures"}

Nurses' gestures Nurses made patients feel reassured, the caring expression in their eyes showed an authentic interest and were able to capture your needs even when these were not evident (Table 7, quote 1). Patients underlined that the nurses' interest was perceived to be authentic when it was accompanied by concrete gestures (Table 7 , quote 2).

Talking to nurses about one's fears and feelings was considered to be important, but patients also underlined that before opening yourself up to nurses, you must be able to trust them and make sure that you are understood (Table 7, quote 3). Also talking about things that 'do not concern the hospital', like sports events was important (Table 7, quote 4).

Patients wanted to receive advice from nurses on how they could manage fatigue but this did not always happen, and according to the patients this was because nurses did not have enough time or had to give the priority to patients who were 'feeling worse than them" (Table 7, quote 5).

With regard to fatigue, some patients reported that nurses considered the onset of this symptom 'normal' or a 'routine'; others considered it something odd they had to deal with (Table 7, quote 6).

When nurses collected data on fatigue, patients felt they were being 'taken in charge'. Some patients underlined the importance of this study and wished that more attention would to be placed on this symptom.

Some patients reported that they had been encouraged to walk, and considered physicians and nurses as their "sports coach". This portrays the competence of health professionals who know how to help these patients achieve important goals, by working on a person's ability, motivation and will power.

Other patients reported that although they did speak to nurses, they did not receive any advice on how to manage fatigue. They remember that sometimes nurses remained in silence, an attitude that was interpreted as 'they are reflecting, they are thinking about it'. Some patients justified the nurses for not giving them any advice, thinking that fatigue is not a problem that is easy to resolve'. 
Table 7 Quotes for Theme IV: "Feeling reassured by the nurses" gestures"

Quote 1, Anna "they worry, look, check, ask what you. They are always there, more than the doctors, and they reassure you"

Quote 2 Gionata "they come back to see how you are, they try to find solutions, they take me for a walk".

Quote 3 Ginevra "As a patient you understand who is the right person and with whom you can open up with. Ok that person speaks like me ... you notice it from the person's attitude"

Quote 4 Giovanni "the focus is not just on the person's feelings, but also on the life that is out there".

Quote 5 Simona "they don't have much time because they're busy doing other things and there are people who are worse off than us. I think it's not easy to manage all this, but I think that in the future they will need to think also of those who feel a bit better".

Quote 6 Agata"Nurses have many things to do and I think: "fatigue is difficult to deal with, for them it is an extra thing".

Others thought that specialized nurses could go more in depth and provide practical advice on how to manage their psychophysical resources.

\section{Theme V "Being informed"}

Being informed about fatigue, knowing its causes and how to control it was very important for patients and helped them play an active role in the care process and understand in advance when certain events may occur (Table 8, quote 1).

Some patients were satisfied with the information they had received and considered the exchange of information between physicians and nurses a positive element (Table 8, quote 2).

Other patients thought that the information they had received was not complete, checked, and not enough time dedicated to providing it, giving rise to a sensation of abandonment (Table 8, quote 3 ). When information was not deemed sufficient, patients consulted other sources (Table 8, quote 4).

\section{The perception of nurses (from the focus groups)}

A total of 15 nurses, ( 3 men and 12 women, aged between 25 and 45) years old took part in two focus groups.

We identified three major themes and their subthemes: Theme I: 'Objectivity and subjectivity in the

\section{Table 8 Quotes for Theme V: "Being informed"}

Quote 1, Ginevra "being informed enables me to have a more commensurate role with nurses, information /knowledge helps me to anticipate things before they happen".

Quote 2, Anna "Receiving accurate and timely answers is very important, being informed made me feel involved".

Quote 3 Claudia "I asked many things both to physicians and nurses, and I have to say that they were very helpful and answered to my questions. However, I felt the need to gain a deeper understanding, I searched the Internet a lot and then I did things my own way, with all the limitations this involved"

Quote 4 Simona, "The information I would need has to more accurate, structured and monitored. In this I felt a little abandoned". assessment of fatigue', Theme 2: 'Nursing contribution in the multidisciplinary management of fatigue' and Theme 3: 'Difficulty evaluating outcomes'.

\section{Theme I: Objectivity and subjectivity in the assessment of fatigue}

The term used by nurses to describe fatigue was 'tiredness', physical and mental, in some cases makes patients feel unmotivated to do things (Table 9, quote 1).

Nurses underlined how this problem was very frequent due to the 'type of patients', who were not 'fit' due to their age and the 'intensive' treatments. Assessing the presence of fatigue was described by nurses as a 'subjective perception', and this generated uncertainty (Table 9, quote 2).

The aspects taken into account were how patients carried out their activities of daily living, how they greeted you, and their willingness to talk. The possibility of considering measurable 'objective' data (e.g. blood tests, vitals signs, etc.) was also considered important. The collection of these data would lead nurses to include the 'fatigue focus' [36] in the nursing records, where a daily assessment would be made to monitor the course of this symptom. In relation to this, some of the nurses reported that they did not use the 'fatigue focus' but rather a focus on what they define as 'something similar to it' (e.g. difficulty moving, or lack of appetite). At times, patients declared that they were feeling weak, describing it as 'a feeling of uneasiness'. The nurses underlined that fatigue is something that they discuss about with other nurses, but rarely during multidisciplinary meetings.

\section{Theme II: "Nursing contribution in the multidisciplinary management of fatigue"}

This theme included two subcategories: those who deal with fatigue, and the nursing management of fatigue.

Those who deal with fatigue The nurses reported that it was important to ensure the multidisciplinary management of fatigue. According to the nurses, the most appropriate health professionals for this are physiotherapists and dieticians. The nurses also declared that nursing plays a key role in the multidisciplinary management of fatigue, but they had two different views about it: some reported that nurses had to be proactive; others instead saw themselves as playing the role of the patient's 'spokesperson'. The nurses debated on this aspect and agreed that it is important to reflect on what is currently done and on what instead could be done (Table 9, quote 3).

The patient's family was also described as an important resource, although nurses had divergent feelings about this, because on one hand families helped, but on 
Table 9 Themes and quotes from the two focus groups with the nurses

\begin{tabular}{|c|c|}
\hline Theme & Quotes \\
\hline $\begin{array}{l}\text { Theme I: } \\
\text { "Objectivity and subjectivity in the assessment } \\
\text { of fatigue" }\end{array}$ & $\begin{array}{l}\text { 1. "It's a kind of tiredness that leaves patients with very little willingness to face the day, with little } \\
\text { motivation" (Focus Group 1, Nurse 1) } \\
\text { 2. "Sometimes, during handover you receive information about how the nurse who was there before you } \\
\text { perceived the patient, but then you personally think that the patient is no longer like that. Maybe because } \\
\text { the patient is feeling better now or we may have different ways of seeing things" (Focus Group 2, Nurse 4) } \\
\text { "Ours is a perception" (Focus Group 1, Nurse 3) }\end{array}$ \\
\hline $\begin{array}{l}\text { Theme II: } \\
\text { "Nursing contribution in the multidisciplinary } \\
\text { management of fatigue" }\end{array}$ & $\begin{array}{l}\text { 3. "We have to reflect on this because I think that in addition to encouraging patients to do things, we } \\
\text { are mostly their spokespersons" (Focus Group 2, Nurse 5) } \\
\text { 4. "Sometimes relatives insist a lot and we let them do things we are not supposed to let them do" (Focus } \\
\text { Group 2, Nurse 3) } \\
\text { "I saw the case of a patient where his wife was present and helped out" (Focus Group 1, Nurse 4) } \\
\text { 5. "When we listen to a patient that talks about this symptom it's a problem for us, sometimes we really } \\
\text { don't know what to do" (Focus Group 2, Nurse 6) } \\
\text { 6. "We do the interventions but in my view, they are just our own initiative, and we don't always feel like } \\
\text { talking about them, or writing a report about them or objectifying them" (Focus Group 2, Nurse 1) } \\
\text { "the thing it that we don't agree on a care plan with our colleagues, we just say: there's this problem, } \\
\text { what shall we do? Each of us does a little of what has already been done before or seen before. There is } \\
\text { no thinking about which interventions need to be implemented in the future." (Focus Group 1, Nurse 8) }\end{array}$ \\
\hline $\begin{array}{l}\text { Theme III: } \\
\text { "Difficulty evaluating outcomes" }\end{array}$ & $\begin{array}{l}\text { 7."Frankly, I'm not sure of the actual benefit I am providing, it may well be an inducted symptom that it } \\
\text { could be due to the patient's treatment". (Focus Group 1, Nurse 5) } \\
\text { "We experience a bit of frustration, in the sense that we do what we can, but what he actually does is } \\
\text { that he just stays in bed". (Focus Group 2, Nurse 7) }\end{array}$ \\
\hline
\end{tabular}

the other, their presence can at times be 'cumbersome' (Table 9, quote 4).

The nursing management of fatigue Fatigue was described as a multifactor symptom, which nurses considered complicated to manage (Table 9, quote 5).

Nurses described interventions such as encouraging patients to take care of their personal hygiene and to get out of bed. They reported that it was important to allow "all the time they needed" but also to "encourage them". In addition, also a better organization of the space available in the patient's room could facilitate the patient's movements.

However, nurses reported that these types of interventions were implemented on their own initiative (Table 9, quote 6). Therefore, there were various ways of addressing fatigue, some nurses focused more on encouraging patient mobility and others on nutrition, almost as if the interventions depended on the nurses' individual sensations or a personal way of viewing the problem.

Other than the interventions made by the nurses, there was also an 'organizational' aspect regarding the procedure to request the specific intervention of other health professionals, such as physiotherapists, dieticians or psychologists.

\section{Theme III: "Difficulty evaluating outcomes"}

The process adopted by the nurses to evaluate the outcomes was poorly structured. The aspects described by the nurses were essentially two: when the patients report that they no longer feel cold and start joking and smiling.
The nurses also underlined the difficulty in evaluating if an outcome was actually the consequence of a nursing intervention or the result of radiotherapy or chemotherapy for instance, and this sometimes led to a sense of frustration (Table 9, quote 7). To address these difficulties, the nurses claimed that it would be useful for them to act upon three aspects: education, use validated tools to measure fatigue, and know the results of the present study.

Finally, the nurses suggested that also the availability of a set of guidelines for an objective assessment of fatigue would be very useful to evaluate the outcomes of their interventions.

\section{Integration of the qualitative and quantitative findings} The Joint display that integrate the qualitative and quantitative findings is reported in Table 10.

\section{Discussion}

The aim of this study was to detect the presence and the intensity of fatigue in hospitalised cancer patients and to describe the perceptions of patients and nurses when they detect and assess this symptom.

In general, there was agreement between patients' and nurses' perspectives, and between quantitative and qualitative data. The only two points for which there was disagreement were: a) the assessment of fatigue, where patients perceived to have received less fatigue assessment compared to what nurses thought they had performed; and b) the management of fatigue, where there was a discrepancy between what nurses said and what was actually reported in the patients' records (Table 10, Joint display). These discrepancy is consistent with the 
Table 10 Joint display for qualitative and quantitative data integration

\begin{tabular}{|c|c|c|c|c|c|}
\hline $\begin{array}{l}\text { QUANTITATIVE } \\
\text { RESULTS }\end{array}$ & $\begin{array}{l}\text { QUALITATIVE } \\
\text { RESULTS } \\
\text { (PATIENTS } \\
\text { INTERVIEWS) }\end{array}$ & $\begin{array}{l}\text { QUALITATIVE } \\
\text { RESULTS (NURSES } \\
\text { FOCUS GROUPS) }\end{array}$ & $\begin{array}{l}\text { AGREEMENT } \\
\text { POINTS }\end{array}$ & $\begin{array}{l}\text { DISAGREEMENT } \\
\text { POINTS }\end{array}$ & CONCLUSIONS \\
\hline BFI questionnaire & THEMES & THEMES & $\mathrm{x}$ & & \multirow{2}{*}{$\begin{array}{l}\text { Both quantitative and qualitative data } \\
\text { show that it is an important issue for } \\
\text { patients and nurses, which has a strong } \\
\text { impact on quality of life. }\end{array}$} \\
\hline $\begin{array}{l}\text { Fatigue and work } \\
\text { activities median = } 5\end{array}$ & $\begin{array}{l}\text { FEELING } \\
\text { POWERLESS AND } \\
\text { AGGRESSIVE } \\
\text { It changes.- you } \\
\text { are different- } \\
\text { influence habit } \\
\text { and social } \\
\text { relations }\end{array}$ & $\begin{array}{l}\text { OBJETIVITIES AND } \\
\text { SUBJECTIVITIES IN THE } \\
\text { ASSESSEMENT OF } \\
\text { FATIGUE }\end{array}$ & & & \\
\hline $\begin{array}{l}\text { Patient perception } \\
\text { nurses' care received: }\end{array}$ & $\begin{array}{l}\text { QUALITATIVE } \\
\text { RESULTS } \\
\text { (PATIENTS } \\
\text { INTERVIEWS) }\end{array}$ & $\begin{array}{l}\text { QUALITATIVE } \\
\text { RESULTS (NURSES } \\
\text { FOCUS GROUPS) }\end{array}$ & $\begin{array}{l}\text { AGREEMENT } \\
\text { POINTS }\end{array}$ & $\begin{array}{l}\text { DISAGREEMENT } \\
\text { POINTS }\end{array}$ & CONCLUSIONS \\
\hline $\begin{array}{l}68.8 \% \text { of the nurses paid } \\
\text { attention to patient's } \\
\text { fatigue }\end{array}$ & $\begin{array}{l}\text { FEELING } \\
\text { REASURED BY } \\
\text { THE NURSES' } \\
\text { GESTURES } \\
\text { BEING } \\
\text { INFORMED }\end{array}$ & $\begin{array}{l}\text { NURSING } \\
\text { CONTRIBUTION IN THE } \\
\text { MULTIDISCIPLINARY } \\
\text { MANAGEMENT OF } \\
\text { FATIGUE }\end{array}$ & $x$ & & $\begin{array}{l}\text { Qualitative and quantitative data confirm } \\
\text { that nurses pay attention to the fatigue } \\
\text { syndrome in patients, despite nurses do } \\
\text { not always report the actions they } \\
\text { implement to manage fatigue and are } \\
\text { scarcely documented. }\end{array}$ \\
\hline
\end{tabular}

53.8\% Nurses provided information on how to ask others to do some activities for them

$57.1 \%$ of patients perceived to have received psychological support
FEELING

REASURED BY

THE PRESENCE

OF FAMILY

MEMBERS

BEING

INFORMED

FEELING

REASURED BY

THE NURSES

GESTURES
Those who deal with $\quad \mathbf{X}$

fatigue

Both the quantitative and the qualitative data (of patients and nurses) underline the importance of caregivers.

\section{X patient quantitative and qualitative data}

53.8\% no information provided by nurses on how to measure fatigue autonomously

$45.5 \%$ no information provided by nurses on how to subdivide the day

$46.2 \%$ no information provided by nurses on how to reduce efforts

$46 \%$ of the time nurses checked patients for fatigue
BEING

INFORMED

BEING

INFORMED

BEING

INFORMED

FEELING

REASURED BY

THE NURSES'

GESTURES
OBJECTIVITY AND

SUBJECTIVITY IN THE

ASSESSMENT OF

FATIGUE
$\mathrm{X}$

$\mathrm{X}$
Patients' records

Difference in reporting fatigue by physicians ( 15 times) and nurses (5 times)
NURSING

CONTRIBUTION IN THE

MULTIDISCIPLINARY

MANAGEMENT OF

FATIGUE

The nursing
Regarding this aspect, there is agreement between patients' quantitative and qualitative data. Nurses do not mention about psychological support for the management of the disease. Probably because this type of psychological support was provided by health professions other than nurses, or because they gave it for granted.

There is agreement between quantitative and qualitative data because the patients confirmed, also in the qualitative data, the importance of being informed. However, this information was sometimes incomplete or was provided only to some patients.
There is inconsistency between what patients and what nurses perceived in relation to the assessment of fatigue. Patients perceived that they had been assessed for fatigue few times, whereas nurses said that they do this assessment, although they underline the difficulty of conducting an objective assessment.

Despite nurses pay attention to fatigue (see positive aspects), in reality it is documented very little in the patients' records and it is sometimes described through other symptoms (nutrition, movement/ exercise, etc.) 
Table 10 Joint display for qualitative and quantitative data integration (Continued)

$$
\begin{aligned}
& \text { management of } \\
& \text { fatigue } \\
& \text { DIFFICULTY } \\
& \text { EVALUATING } \\
& \text { OUTCOMES }
\end{aligned}
$$

literature, where fatigue is reported to be still inadeguately and inconsistently addressed by health professionals in many institutions [30, 31], underlining the importance of adopting a more standardized approach.

The results of the present study showed that patients had already developed fatigue also during the seven days prior to its detection (66\%). Both patients and nurses were aware that fatigue had a physical and psychological impact, thus compromising their ability to keep up with the normal activities of everyday life. Through the questionnaire, the patients described how fatigue interfered with their work activities and with the activities of daily life in general. This finding was also reported by Wu \& Davis [49] and Borneman et al. [9].

Participants described how the onset of fatigue was 'sudden' and unrelated to a precise cause, and was often a source of frustration and anger, as also reported by Scott et al. [19]. The nurses reported that detecting the onset of fatigue was important, but at the same time very difficult to perform and assess in an 'objective' manner. This difficulty also emerged from the analysis of the nursing documentation regarding the patients included in this study. In fact, there were inconsistencies in the way fatigue was assessed across medical records (15 times) and across nursing records (5 times), as already stated. In the nursing records, we noticed that fatigue was not always reported, but rather the problems that were related to it, such as physical exercise, rest and sleep, or loss of appetite (17 times). As reported in the literature $[1,6,30,31]$ we also found that nurses tended to underestimate the perception of fatigue more than patients. One possible reason for this could be the widespread belief that it is an unavoidable, complex symptom for which you do not really know what to do. (Table 9, quote 5).

The strategies adopted by the patients to deal with fatigue, such as physical activity or changing their sleep/wake rhythms, were similar to those described by Borneman [9] and recommended in the literature, but the innovative element reported by some of our patients was the importance of acting on will power, concentrating on positive things and removing negative thoughts or situations.

For the patients, it was very important to be informed about fatigue and how to deal with it, because this helps them to find the right strategies and play an active role in managing this symptom. However, the information provided by nurses and physicians was not always considered to be sufficient and as a consequence they sometimes consulted other sources (e.g. the Internet) as also reported in other studies [50-52]. Information was important also for nurses, who underlined a twofold difficulty. On one hand, the difficulty identifying effective interventions on which everyone agreed for the management of this symptom; and on the other, the difficulty in playing a proactive role within the multidisciplinary team to attract more attention on the need to consistently assess and manage fatigue.

The presence of nurses was very important for our patients because they made them feel reassured, and free to talk openly of what they experienced and their fears, similarly to another study [52]. Patients wanted to receive more advice from nurses, but this did not always happen, and patients thought that this was due to the nurses' lack of time and the actual difficulty in dealing with fatigue. As mentioned above, also nurses thought it was difficult to intervene effectively on fatigue and declared that those interventions they do implement were often the result of subjective initiatives rather than a structured planned intervention. In addition, nurses also declared that it was difficult to evaluate the outcomes of the interventions that addressed fatigue due to the lack of validated tools.

Mackereth et al. [50] describe the patients' frustration for their family members' inability to understand their fatigue, instead this aspect did not emerge from our study. In fact, our patients said that it was very important to be with their family members and friends, because they felt understood and supported by them. The nurses also thought that the family's support was very important for these patients and underlined their willingness to listen to their requests and observations, and involve them in the care process. Therefore, the involvement of family members (and/or friends) in the management of this symptom over time appears to be a relevant aspect.

\section{Limitations}

This study has some limitations that need to be considered. Firstly, this was a monocentric study linked to a specific context, therefore the results should be interpreted in the light of this. Furthermore, we did not calculate the sample size for the quantitative data. Secondly, the patients' records were very difficult to consult because data were fragmented and not easy to find, therefore some relevant data may have been missed. Moreover, it is likely that the nurses did not report all the measures they adopted to manage fatigue and the paucity of reported interventions could be the 
consequence of this. Finally, only 22 patients responded to the BFI questionnaire at discharge, and only 20 patients responded to the questionnaire about perceived nursing care received to deal with their fatigue, and this may have limited our results.

\section{Implications for clinical practice and nursing}

Despite fatigue is a widespread symptom and its impact on cancer patients is significant, it still tends to be underestimated by health professionals. As suggested by the participants of this study, to bridge this gap it is necessary to raise major awareness in health professionals and increase their knowledge about fatigue, as well as their ways of treating it. With regard to health professionals' awareness, it could be helpful to reflect together with them on the results of the present study (as well as other studies), thus simulating a reflective thinking approach. Instead, with regard to health professionals' knowledge, it would be appropriate to conduct specific interprofessional educational sessions on fatigue, and to take into account the patients' indications (i.e. having appropriate advice and being supported in their motivation).

With regard to nurses' practice, the various phases of the nursing process need to be improved, starting from the assessment, to the interventions, multi-professional collaboration and outcome evaluation. Once all these aspects have been clarified and negotiated, they could constitute a specific guideline to be implemented within the health organization and then periodically updated.

\section{Conclusions}

When comparing the perceptions of the patients with those of the nurses who were caring for them, we identified some interesting aspects that could be used to change health professionals' approach to the way they manage fatigue, in addition to what the literature recommends.

The patients adopted various personal strategies that helped them cope with fatigue, but they also suggested to the nurses some possible interventions that could be helpful for them. On the other hand, nurses could gain important knowledge from scientific evidence and by listening to their patients and improve the effectiveness of their professional practice. Reviewing and discussing these data together with the team of health professionals that produced them, could help them become more aware of the issues related to fatigue and facilitate the change process within their organization.

\section{Abbreviations}

BFI: Brief fatigue inventory; SPSS: Statistical package for the social sciences; NCCN: National Comprehensive Cancer Network; Q1: First quartile; Q3: Third quartile; IQR: Iterquartile range; SD: Standard deviation; BMI: Body mass index LOS: Length of stay; Me: Median

\section{Supplementary Information}

The online version contains supplementary material available at https://doi. org/10.1186/s12912-021-00699-9.

Additional file 1. Legitimation criteria.

\section{Acknowledgments}

We would like to thank the managers and nurses of the Oncology Institute of Southern Switzerland (IOSI) for the contribution given to the research and the Advisory Board for Clinical Research of the Ente Ospedaliero Cantonale (ABREOC) that funded it.

\section{Authors' contributions}

$D V, M B$ and CP contributed to the study design, DV, LB, AT, CP, NP, DS, LM contributed to acquisition of data; LB contributed to quantitative data analysis and interpretation; DV and AT contributed to qualitative data analysis and interpretation; AT, DV and LB contributed to mixed data interpretation; DV, LB, AT drafted the manuscript; DV, MB, CP, DS, LM, NP revised it critically for important intellectual content; all authors approved the final submitted version.

\section{Funding}

The study was funded by the Advisory Board for Clinical Research of the Ente Ospedaliero Cantonale (ABREOC).

\section{Availability of data and materials}

The data and all supporting materials used in our manuscript are freely available to any scientist wishing to use them from the corresponding author on request.

\section{Declarations}

Ethics approval and consent to participate

The study was approved by the Canton Ticino (Bellinzona, Switzerland) Ethics Committee (Reference number: CE 2904, 31-7-2015). The study was carried out in accordance with the Codes of Ethics of the World Medical Association (Declaration of Helsinki). All the participants provided a written informed consent and data confidentiality was guaranteed.

Consent for publication

Not applicable

\section{Competing interests}

The authors have no conflict of interest to disclose.

\section{Author details}

${ }^{1}$ Nursing Research and Development Unit, Oncology Institute of Southern Switzerland (IOSI), Via Gallino, 12, 6500 Bellinzona, Switzerland. ${ }^{2}$ Department of Business Economics, Health and Social Care, University of Applied Sciences and Arts of Southern Switzerland (SUPSI), Manno, Switzerland. ${ }^{3}$ Clinical Trial Unit, Oncology Institute of Southern Switzerland (IOSI), Via Gallino, 12, 6500 Bellinzona, Switzerland. ${ }^{4}$ Department of Surgical, Medical and Molecular Pathology and Critical Care, University of Pisa, Pisa, Italy. ${ }^{5}$ Department of Nursing, Oncology Institute of Southern Switzerland (IOSI), Via Gallino, 12, 6500 Bellinzona, Switzerland.

Received: 19 February 2021 Accepted: 19 August 2021

Published online: 28 September 2021

\section{References}

1. Berger AM, Mooney K, Alvarez-Perez A, Breitbart WS, Carpenter KM, Cella D, et al. Cancer-related fatigue, version 2.2015. J Natl Compr Cancer Netw. 2015;13(8):1012-39. https://doi.org/10.6004/jnccn.2015.0122.

2. Pearson EJM, Morris ME, MCKinstry CE. Cancer-related fatigue: appraising evidence-based guidelines for screening, assessment and management. Support Care Cancer Off J Multinatl Assoc Support Care Cancer. 2016;24(9): 3935-42. https://doi.org/10.1007/s00520-016-3228-9.

3. Prue G, Rankin J, Allen J, Gracey J, Cramp F. Cancer-related fatigue: a critical appraisal. Eur J Cancer. 2006;42(7):846-63. https://doi.org/10.1016/j.ejca.2 005.11.026. 
4. Koornstra RHT, Peters M, Donofrio S, van den Borne B, de Jong FA. Management of fatigue in patients with cancer -- a practical overview. Cancer Treat Rev. 2014;40(6):791-9. https://doi.org/10.1016/j.ctrv.2014.01.004

5. Wang XS. Pathophysiology of cancer-related fatigue. Clin J Oncol Nurs. 2008;12(5 Suppl):11-20. https://doi.org/10.1188/08.CJON.S2.11-20.

6. National Comprehensive Cancer Network ${ }^{\circledR}$. Clinical practice guidelines in oncology- cancer-related fatigue [Internet]. First version, December 2020. 2021. Available from: https://www.nccn.org.

7. Mustian KM, Morrow GR, Carroll JK, Figueroa-Moseley CD, Jean-Pierre P, Williams GC. Integrative nonpharmacologic behavioral interventions for the management of cancer-related fatigue. Oncologist. 2007;12(Suppl 1):52-67. https://doi.org/10.1634/theoncologist.12-S1-52.

8. Bower JE. Cancer-related fatigue--mechanisms, risk factors, and treatments. Nat Rev Clin Oncol. 2014;11(10):597-609. https://doi.org/10.1038/nrclinonc.2 014.127.

9. Borneman T, Piper BF, Koczywas M, Munevar CM, Sun V, Uman GC, et al. A qualitative analysis of cancer-related fatigue in ambulatory oncology. Clin J Oncol Nurs. 2012;16(1):E26-32. https://doi.org/10.1188/12.CJON.E26-E32.

10. Escalante CP, Manzullo EF. Cancer-related fatigue: the approach and treatment. J Gen Intern Med. 2009;24(Suppl 2):S412-6. https://doi.org/10.1 007/s11606-009-1056-z.

11. Berger AM, Mitchell SA, Jacobsen PB, Pirl WF. Screening, evaluation, and management of cancer-related fatigue: ready for implementation to practice? CA Cancer J Clin. 2015;65(3):190-211. https://doi.org/10.3322/caa c.21268.

12. Nicklin J, Cramp F, Kirwan J, Greenwood R, Urban M, Hewlett S. Measuring fatigue in rheumatoid arthritis: a cross-sectional study to evaluate the Bristo rheumatoid arthritis fatigue multi-dimensional questionnaire, visual analog scales, and numerical rating scales. Arthritis Care Res. 2010;62(11):1559-68. https://doi.org/10.1002/acr.20282.

13. Mitchell SA, Hoffman AJ, Clark JC, Degennaro RM, Poirier P, Robinson CB, et al. Putting evidence into practice: an update of evidence-based interventions for cancer-related fatigue during and following treatment. Clin J Oncol Nurs. 2015;18(6):38-58.

14. Johansson S, Kottorp A, Lee KA, Gay CL, Lerdal A. Can the fatigue severity scale 7-item version be used across different patient populations as a generic fatigue measure--a comparative study using a Rasch model approach. Health Qual Life Outcomes. 2014;12(1):24. https://doi.org/10.11 86/1477-7525-12-24

15. Hewlett S, Dures E, Almeida C. Measures of fatigue: Bristol Rheumatoid Arthritis Fatigue Multi-Dimensional Questionnaire (BRAF MDQ), Bristol Rheumatoid Arthritis Fatigue Numerical Rating Scales (BRAF NRS) for severity, effect, and coping, Chalder Fatigue Questionnaire (CFQ), checklist. Arthritis Care Res. 2011; 63(Suppl 1):S263-86. https://doi.org/10.1002/acr.20579.

16. Piper BF, Borneman T, Sun VC-Y, Koczywas M, Uman G, Ferrell B, et al. Cancerrelated fatigue: role of oncology nurses in translating National Comprehensive Cancer Network assessment guidelines into practice. Clin J Oncol Nurs. 2008; 12(5 Suppl):37-47. https://doi.org/10.1188/08.CJON.S2.37-47.

17. Hilarius DL, Kloeg PH, van der Wall E, Komen M, Gundy CM, Aaronson NK. Cancer-related fatigue: clinical practice versus practice guidelines. Support Care Cancer Off J Multinatl Assoc Support Care Cancer. 2011;19(4):531-8. https://doi.org/10.1007/s00520-010-0848-3.

18. Knowles G, Borthwick D, McNamara S, Miller M, Leggot L. Survey of nurses' assessment of cancer-related fatigue. Eur J Cancer Care (Engl). 2000;9(2): 105-13. https://doi.org/10.1046/j.1365-2354.2000.00197.x.

19. Scott JA, Lasch KE, Barsevick AM, Piault-Louis E. Patients' experiences with cancer-related fatigue: a review and synthesis of qualitative research. Oncol Nurs Forum. 2011;38(3):E191-203. https://doi.org/10.11 88/11.ONF.E191-E203.

20. Campos MPO, Hassan BJ, Riechelmann R, Del Giglio A. Cancer-related fatigue: a practical review. Ann Oncol Off J Eur Soc Med Oncol. 2011;22(6): 1273-9. https://doi.org/10.1093/annonc/mdq458.

21. Bruera E, Kuehn N, Miller MJ, Selmser P, Macmillan K. The Edmonton Symptom Assessment System (ESAS): a simple method for the assessment of palliative care patients. J Palliat Care. 1991;7(2):6-9. https://doi.org/10.11 77/082585979100700202.

22. Cramp F, Byron-Daniel J. Exercise for the management of cancer-related fatigue in adults. Cochrane Database Syst Rev. 2012;11:CD006145.

23. Ebede CC, Jang Y, Escalante CP. Cancer-related fatigue in cancer survivorship. Med Clin North Am. 2017;101(6):1085-97. https://doi.org/10.101 6/j.mcna.2017.06.007.
24. Finnegan-John J, Molassiotis A, Richardson A, Ream E. A systematic review of complementary and alternative medicine interventions for the management of cancer-related fatigue. Integr Cancer Ther. 2013;12(4):27690. https://doi.org/10.1177/1534735413485816.

25. Minton O, Richardson A, Sharpe M, Hotopf M, Stone P. A systematic review and meta-analysis of the pharmacological treatment of cancer-related fatigue. J Natl Cancer Inst. 2008;100(16):1155-66. https://doi.org/10.1093/ jnci/djn250.

26. Smith C, Carmady B, Thornton C, Perz J, Ussher JM. The effect of acupuncture on post-cancer fatigue and well-being for women recovering from breast cancer: a pilot randomised controlled trial. Acupunct Med. 2013 31(1):9-15. https://doi.org/10.1136/acupmed-2012-010228.

27. Taso C-J, Lin H-S, Lin W-L, Chen S-M, Huang W-T, Chen S-W. The effect of yoga exercise on improving depression, anxiety, and fatigue in women with breast cancer: a randomized controlled trial. J Nurs Res. 2014;22(3):155-64. https://doi.org/10.1097/jnr.0000000000000044.

28. Wanchai A, Armer JM, Stewart BR. Nonpharmacologic supportive strategies to promote quality of life in patients experiencing cancer-related fatigue: a systematic review. Clin J Oncol Nurs. 2011;15(2):203-14. https://doi.org/10.11 88/11.CJON.203-214

29. de Raaf PJ, de Klerk C, Timman R, Busschbach JJV, Oldenmenger WH, van der Rijt CCD. Systematic monitoring and treatment of physical symptoms to alleviate fatigue in patients with advanced cancer: a randomized controlled trial. J Clin Oncol. 2013;31(6):716-23. https://doi.org/10.1200/JCO.2012.44.421 6.

30. Williams LA, Bohac C, Hunter S, Cella D. Patient and health care provider perceptions of cancer-related fatigue and pain. Support Care Cancer Off J Multinatl Assoc Support Care Cancer. 2016;24(10):4357-63. https://doi.org/1 0.1007/s00520-016-3275-2.

31. Pearson EJM, Morris ME, McKinstry CE. Cancer-related fatigue: a survey of health practitioner knowledge and practice. Support Care Cancer Off J Multinatl Assoc Support Care Cancer. 2015;23(12):3521-9. https://doi.org/1 0.1007/s00520-015-2723-8.

32. Morse JM. Approaches to qualitative-quantitative methodological triangulation. Nurs Res. 1991;40(2):120-3. https://doi.org/10.1097/00006199-1 99103000-00014.

33. Hong QN, Pluye P, Bujold M, Wassef M. Convergent and sequential synthesis designs: implications for conducting and reporting systematic reviews of qualitative and quantitative evidence. Syst Rev. 2017;6(1):61. https://doi.org/10.1186/s13643-017-0454-2.

34. Shahid A, Wilkinson K, Marcu S, Shapiro CM. Brief fatigue inventory. In: STOP, THAT and One Hundred Other Sleep Scales; 2011.

35. Catania G, Bell C, Ottonelli S, Marchetti M, Bryce J, Grossi A, et al. Cancerrelated fatigue in Italian cancer patients: validation of the Italian version of the Brief Fatigue Inventory (BFI). Support Care Cancer Off J Multinatl Assoc Support Care Cancer. 2013;21(2):413-9. https://doi.org/10.1007/s00520-012-1 539-z.

36. Lampe S. Focus charting: documentation for patient-centered care. Bloomington: Creative Health Care Management; 1997.

37. Polit DF, Beck CT. Nursing research: generating and assessing evidence for nursing practice. New York: Lippincott Williams \& Wilkins; 2008.

38. Braun V, Clarke V. Using thematic analysis in psychology. Qual Res Psychol. 2006;3(2):77-101. https://doi.org/10.1191/1478088706qp063oa.

39. Elo S, Kyngas $H$. The qualitative content analysis process. J Adv Nurs. 2008; 62(1):107-15. https://doi.org/10.1111/j.1365-2648.2007.04569.x.

40. Flick U. An introduction to qualitative research. London: Sage Publications Limited; 2018.

41. Guba EG, Lincoln YS. The Jossey-Bass higher and adult education series and the Jossey-Bass social and behavioral science series. Eff Eval Improv Useful Eval results through responsive Nat approaches San Fr CA, US Jossey-Bass. 1981;

42. Carnevale FA. Authentic qualitative research and the quest for methodological rigour. Can J Nurs Res. 2002;34(2):121-8.

43. Fetters MD, Curry LA, Creswell JW. Achieving integration in mixed methods designs-principles and practices. Health Serv Res. 2013;48(6 Pt 2):2134-56. https://doi.org/10.1111/1475-6773.12117.

44. Younas A, Pedersen M, Tayaben JL. Review of mixed-methods research in nursing. Nurs Res. 2019;68(6):464-72. https://doi.org/10.1097/NNR. 0000000000000372.

45. Younas A, Pedersen M, Durante A. Characteristics of joint displays illustrating data integration in mixed-methods nursing studies. J Adv Nurs. 2020;76(2): 676-86. https://doi.org/10.1111/jan.14264. 
46. Guetterman TC, Fetters MD, Creswell JW. Integrating quantitative and qualitative results in health science mixed methods research through joint displays. Ann Fam Med. 2015;13(6):554-61. https://doi.org/10.1370/afm.1865.

47. Younas A, Parveen Rasheed S, Zeb H. Using legitimation criteria to establish rigour in sequential mixed-methods research. Nurs Res. 2020;28(3):44-51. https://doi.org/10.7748/nr.2020.e1727.

48. Onwuegbuzie AJ, Johnson RB. The validity issue in mixed research. Res Sch. 2006;13(1):48-63.

49. Wu H-S, Davis JE. Definition, prevalence and characteristics of sudden exhaustion: a possible syndrome of fatigue in cancer? Support Care Cancer Off J Multinatl Assoc Support Care Cancer. 2013;21(2):609-17. https://doi. org/10.1007/s00520-012-1555-Z

50. Mackereth P, Farrell C, Bardy J, Molassiotis A, Finnegan-John J. Legitimising fatigue after breast-cancer treatment. Br J Nurs. 2015;24(4):S4, S6, S8-12. https://doi.org/10.12968/bjon.2015.24.Sup4.S4

51. Spichiger E, Rieder E, Muller-Frohlich C, Kesselring A. Fatigue in patients undergoing chemotherapy, their self-care and the role of health professionals: a qualitative study. Eur J Oncol Nurs Off J Eur Oncol Nurs Soc. 2012;16(2):165-71. https://doi.org/10.1016/j.ejon.2011.05.002.

52. Tolotti A, Pedrazzani C, Bonetti L, Bianchi M, Valcarenghi D. Patients' and nurses' perceptions of the effectiveness of an oral cancer agent education process. Cancer Nurs. 2021:44(3):E151-62 Available from: https://journals. Iww.com/10.1097/NCC.0000000000000790

\section{Publisher's Note}

Springer Nature remains neutral with regard to jurisdictional claims in published maps and institutional affiliations.

- fast, convenient online submission

- thorough peer review by experienced researchers in your field

- rapid publication on acceptance

- support for research data, including large and complex data types

- gold Open Access which fosters wider collaboration and increased citations

- maximum visibility for your research: over $100 \mathrm{M}$ website views per year

At BMC, research is always in progress.

Learn more biomedcentral.com/submissions 